\title{
Constrictive bronchiolitis and ulcerative colitis
}

\author{
Heather Ward MD FRCPC ${ }^{1}$, Kendra L Fisher MD FRCPC ${ }^{2}$, \\ Ranjit Waghray MBBS FRCPC SCAP ${ }^{3}$, Jody L Wright BSc MD FRCPC ${ }^{4}$, \\ Sharon E Card MD MSc FRCPC ${ }^{5}$, Donald W Cockcroft MD FRPCC ${ }^{1}$ \\ ${ }^{1}$ Division of Respiratory Medicine; ${ }^{2}$ Department of Medical Imaging, \\ Royal University Hospital; ${ }^{3}$ Department of Pathology, St Paul's Hospital, Saskatoon, \\ Saskatchewan; ${ }^{4}$ Department of Pathology, University of British Columbia, Vancouver, \\ British Columbia; ${ }^{5}$ Division of Internal Medicine, Royal University Hospital, \\ Saskatoon, Saskatchewan
}

\begin{abstract}
H Ward, KL Fisher, R Waghray, JL Wright, SE Card, DW Cockcroft. Constrictive bronchiolitis and ulcerative colitis. Can Respir J 1999;6(2):197-200.
\end{abstract}

Pulmonary complications occur in an estimated $0.21 \%$ of patients with inflammatory bowel disease. The most common presentation of pulmonary manifestations is large airway disease, such as tracheobronchitis, chronic bronchitis or bronchiectasis. Small airway disease, such as constrictive bronchiolitis or bronchiolitis obliterans with organizing pneumonia, is less frequently reported, and is described as occurring in isolation from large airway disease. A case of a postcolectomy ulcerative colitis in a patient who has both large airway involvement, tracheobronchitis and bronchiectasis, and constrictive bronchiolitis is presented.

Key Words: Inflammatory bowel disease, Large airway disease, Pulmonary complications, Small airway disease

\section{Bronchiolite constrictive et colite ulcéreuse}

RÉSUMÉ : Les complications pulmonaires surviennent chez environ $0,21 \%$ des patients atteints d'une maladie inflammatoire de l'intestin. La présentation la plus courante des épisodes pulmonaires est la maladie des grosses voies aériennes, comme la trachéo-bronchite, la bronchite chronique ou les bronchectasies. La maladie des petites voies aériennes, comme la bronchiolite constrictive ou la bronchiolite oblitérante avec pneumonie organisée, est moins fréquemment rapportée, et est décrite comme survenant indépendamment de la maladie des grosses voies aériennes. On décrit le cas d'un patient qui après une colectomie pour colite ulcéreuse présente à la fois une atteinte des grosses voies aériennes, trachéo-bronchite et bronchectasies, et une bronchiolite constrictive.
$\mathrm{E}^{x}$ xtraintestinal manifestations are well documented occurrences in patients with ulcerative colitis; however, pulmonary complications were only first described in a case series by Kraft et al (1) in 1976. Case presentations of airway, interstitial, pleural and vascular involvement have all been reported since then (2). The estimated incidence of pulmo- nary complications with inflammatory bowel disease is $0.21 \%$ (3), and the majority of complications ccur in patients with ulcerative colitis $(2,4)$. Large airway disease, such as tracheobronchitis, chronic bronchitis or bronchiectasis, is most common, while small airway pathology, such as constrictive bronchiolitis and bronchiolitis obliterans with or-

Correspondence and reprints: Dr Donald W Cockcroft, Division of Respiratory Medicine, Department of Medicine, 


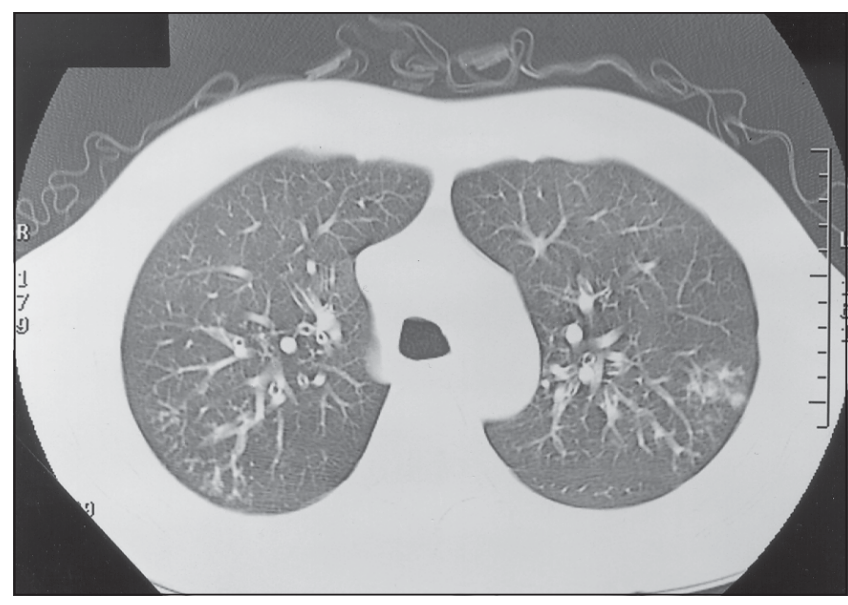

Figure 1) Central bronchial wall thickening 'tree-in-bud' appearance peripherally indicating small airway disease which is contrasted anteriorly by more normal lung

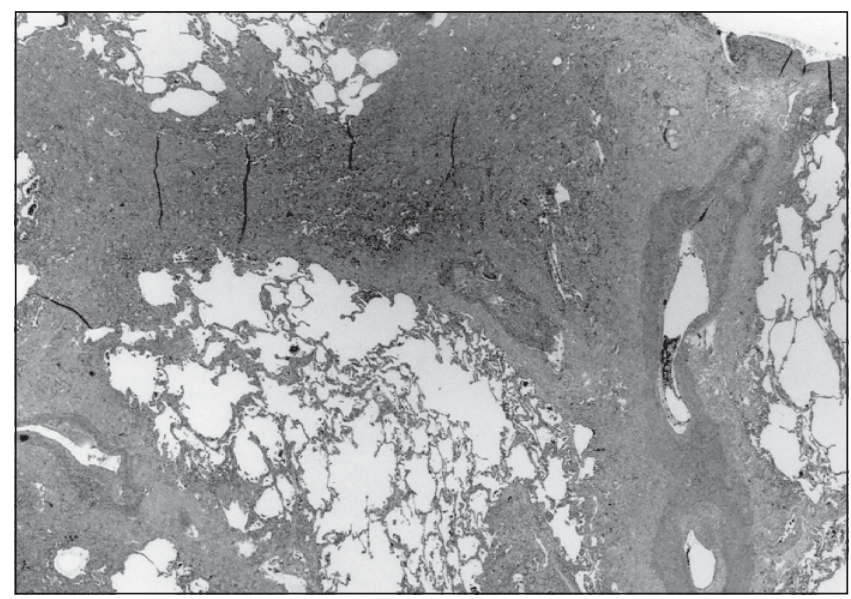

Figure 2) Bronchiolocentric fibrosis, most prominent on the left side, involving several bronchovascular units. Alveoli are spared. Hematoxylin and eosin stain $\times 20$

ganizing pneumonia, is infrequently reported (2). Involvement of the entire bronchial tree is rare. We present the case of a patient with constrictive bronchiolitis and large airway disease, consisting of tracheobronchitis and bronchiectasis, complicating ulcerative colitis.

\section{CASE PRESENTATION}

A 44-year-old, lifetime nonsmoking farmer with a past history of thalassemia minor presented in 1987 at age 35 years with clinically diagnosed and biopsy-proven ulcerative colitis. Gastrointestinal symptoms progressed despite treatment with prednisone, salazopyrin and imodium, and, after nine months, a total colectomy was done. All medications were discontinued following the colectomy. Joint symptoms consisting of morning stiffness, migratory polyarthralgias, and polyarthritis involving hands, knees, hips and ankles began before his colectomy, and persisted postoperatively; a diagnosis of enteropathic arthritis was made. Treatment with nonsteriodal anti-inflammatory drugs was unsuccessful, and salazopyrin $1000 \mathrm{mg}$ twice daily and prednisone $10 \mathrm{mg}$ daily

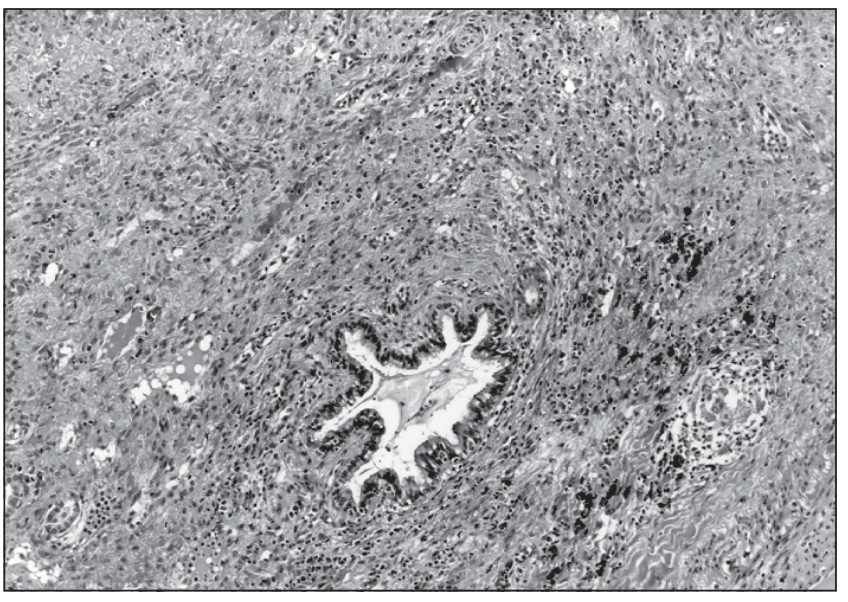

Figure 3) Small constricted bronchiole with mucous plug, chronic inflammation and extensive peribronchiolar fibrosis. Hematoxylin and eosin stain $\times 100$

was commenced in 1994. Before resuming prednisone and salazopyrin, the patient developed a productive cough with exertional dyspnea, and, on pulmonary function testing, forced expiratory volume in $1 \mathrm{~s}\left(\mathrm{FEV}_{1}\right)$ was $2.90 \mathrm{~L} / \mathrm{min}(68 \%$ predicted), ( $\mathrm{FEV}_{1} /$ forced vital capacity ratio of $\left.56 \%\right)$, and the carbon monoxide diffusing capacity of the lungs was $66 \%$ predicted. Bronchoscopy, done in 1993, demonstrated tracheal and bronchial inflammation with thick secretions that were culture negative. Medical treatment included inhaled beclomethasone dipropionate $250 \mathrm{~g}$ two puffs bid and inhaled salbutamol as needed. Exertional dyspnea, cough with sputum (125 mL per day), occasional hemoptysis and weight loss persisted despite salazopyrin $1000 \mathrm{mg}$ bid, prednisone 10 to $20 \mathrm{mg}$ per day, inhaled corticosteroids and ventolin.

In 1997, three-and-a-half years after the onset of respiratory symptoms, $\mathrm{FEV}_{1}$ had declined to $1.67 \mathrm{~L} / \mathrm{min}$ (44\% predicted), and the patient was admitted to hospital for further investigations. He continued to have asymmetric migratory polyarthralgias and a history compatible with dactylitis, again suggestive of enteropathic arthritis. Physical examination was normal except for scattered inspiratory and expiratory crackles, and there were no wheezes on auscultation of the chest. Oxygen saturation was $94 \%$ on room air. Laboratory results included a white blood cell count of $13 \times 10^{9} / \mathrm{L}$, hemoglobin $120 \mathrm{~g} / \mathrm{L}$ with a mean corpuscular volume $64.6 \mathrm{fl}$, rheumatoid factor $1 / 493 \mathrm{KU} / \mathrm{L}$, an anti-nuclear antigen (ANA) titre $1 / 320$, anti-dsDNA $1 / 32 \mathrm{KU} / \mathrm{L}$ and a polyclonal gammopathy. Sweat chloride was $24 \mathrm{mmol} / \mathrm{L}$. There was bronchial and bronchiolar wall thickening, and a suggestion of multiple peripheral 'nodules' on chest radiograph having the appearance of bronchiolar wall thickening with possible mucoid impaction. There was a small $1 \mathrm{~cm}$ nodule in the left upper lobe with apparent cavitation. A standard and high resolution computed tomography (CT) scan showed both central and peripheral bronchial and bronchiolar wall thickening with associated bronchiolectasis. There was a 'tree-inbud' appearance consistent with distal small airway mucoid 
TABLE 1

Pulmonary function tests of patient with constrictive bronchiolitis and ulcerative colitis

\begin{tabular}{|c|c|c|c|c|}
\hline & \multicolumn{2}{|c|}{ October 1997} & \multirow{2}{*}{$\begin{array}{c}\text { October } 1998 \\
\text { Actual }\end{array}$} & \multirow[b]{2}{*}{$\%$ predicted } \\
\hline & Actual & $\%$ predicted & & \\
\hline Forced vital capacity (FVC) & 3.14 & 63 & 4.34 & 87 \\
\hline Forced expiraotry volume in $1 \mathrm{~s}\left(\mathrm{FEV}_{1}\right)$ & 1.72 & 46 & 2.73 & 73 \\
\hline $\mathrm{FEV}_{1} / \mathrm{FVC}$ & $55 / 75$ & & $63 / 75$ & \\
\hline Total lung capacity & 5.35 & 78 & 6.89 & 100 \\
\hline Carbon monoxide diffusion capacity of the lungs & 28.55 & 75 & 26.75 & 71 \\
\hline Prescription prednisone $(\mathrm{mg})$ & 0 & & 20 & \\
\hline Azathioprine (mg) & 0 & & 150 & \\
\hline
\end{tabular}

impaction (Figure 1). Mediastinal and bilateral hilar adenopathy were seen, and CT scan provided no evidence of interstitial lung disease. Diffuse inflammation of the trachea and mainstem bronchi with exudate bilaterally was seen on bronchoscopy. An open lung biopsy was completed, and histological examination showed large areas of rounded fibrosis that were situated adjacent to muscular pulmonary arteries (Figure 2). On elastic stain, a fragmented elastic lamina proved that the areas were obliterated bronchioles. In some airways, a partial lumen remained but was distorted and irregular. The fibrous tissue had largely replaced the muscularis and had markedly increased the volume of the adventitial compartment of the airway. There were no granulation tissue polyps or organizing pneumonia, indicating that the airway lesions were the result of a rather marked degree of constrictive bronchiolitis (Figure 3).

Prednisone $20 \mathrm{mg}$ and azathioprine $150 \mathrm{mg}$ per day were started. At an eight-month follow-up clinic visit, the patient had symptomatic improvement of exertional dyspnea, cough and sputum production. $\mathrm{FEV}_{1}$ had improved from 1.67 to 2.85 , and chest radiograph had improved (Table 1). A repeat CT scan completed 15 months after initiating treatment showed significant improvement in the 'tree-in-bud' appearance, with a marked decrease in the central and peripheral bronchial and bronchiolar wall thickening; however, moderate predominantly bronchial wall thickening and mild bronchiolectasis persisted in both lower lobes. Mediastinal and hilar adenopathy had also largely regressed.

\section{DISCUSSION}

Constrictive bronchiolitis is an infrequently reported complication of ulcerative colitis, and each case report has unique characteristics that expand our knowledge of clinical presentation, pathology and treatment. Only two of 33 patients in the largest reported case series by Camus et al (2) had small airway disease. The three case reports in the literature of constrictive bronchiolitis had different clinical presentations to ours $(3,5,6)$. One patient had ulcerative colitis and no cough or sputum production, but also had exertional dyspnea, severe airflow obstruction, a negative rheumatoid factor and ANA, and biopsy-proven constrictive bronchiolitis $(2,5)$. The second patient had dyspnea, productive cough, moderate airflow obstruction and bronchoscopy changes suggesting chronic bronchitis beginning before the diagnosis of colitis. This patient also had a negative bronchography for bronchiectasis and a lung biopsy demonstrating diffuse panbronchiolitis (3). A third had exertional dyspnea and a nonproductive cough, with a normal bronchoscopy and a lung biopsy showing obliterative bronchiolitis (6). None of these patients had any other extraintestinal manifestations of ulcerative colitis. Our patient had systemic symptoms of weight loss and articular involvement compatible with entropathic arthritis but not clinically suggestive of rheumatoid arthritis despite an elevated rheumatoid factor. He had similar respiratory symptoms to the previously reported cases, including exertional dyspnea, productive cough and moderate airflow obstruction on pulmonary function testing. Both chest radiograph and CT scan were suggestive of large and small airway pathology. He had marked improvement in clinical and radiological findings with prednisone and azathioprine.

Sulfasalazine-associated lung disease is a rare occurrence, and is described most frequently as patchy bilateral lung infiltrates in the mid to upper lung fields with transient mild eosinophilia in a patient presenting with fever and dry cough. The symptoms and chest radiograph changes usually resolve by discontinuing sulfasalazine and starting therapy with prednisone (7). One case of bronchiolitis obliterans with organizing pneumonia has been described in association with sulfasalazine; however, no cases of constrictive bronchiolitis have been described in association with sulfasalazine $(8,9)$. Our patient's respiratory symptoms began before the resumption of sulfasalzine for his musculoskeletal symptoms.

The pathogenesis of pulmonary manifestations in inflammatory bowel disease remains under speculation. Nearly half of the cases of airway involvement occur postcolectomy, and one suggestion has been that the focus of inflammation switches from the gastrointestinal tract to the lung after surgery $(2,10)$. The embryological gut source of both the lung and gastrointestinal tract may account for a common target of inflammation at both epithelial sites (6). There is no predictive serology for the development of lung pathology. Rheumatoid factor is secreted by mucosa of the gastrointestinal tract (11) and can be present in the serum of patients with inflammatory bowel disease, but there is no correlation between titres and disease activity or extraintestinal manifestations (12). ANA is present in $25 \%$ and peri anti- 
nuclear cytoplasmic antibody in $68 \%$ to $86 \%$ of ulcerative colitis patients, again with unknown etiological or clinical implications $(13,14)$. The positive serology results suggest an autoimmune etiology for inflammatory bowel disease and its systemic manifestations, but the mechanism is unknown. There is an insufficient number of case descriptions of pulmonary involvement in ulcerative colitis to postulate the disease process or the extent of potential lung involvement.

Case series of large airway involvement in ulcerative colitis describe tracheobronchitis, chronic "suppurative" bronchitis or bronchiectasis as being anatomically localized, with no continuous involvement of the large and small airways $(2,5)$. Constrictive bronchiolitis is usually a lesion of the bronchioles with luminal narrowing by scarring (15). Chronic productive cough was defined by chronic bronchitis; bronchiectasis was characterized by typical radiographical findings (chest radiograph, bronchography and CT scan); and tracheobronchitis was defined by the bronchoscopy findings of inflammation and edema. The localized upper airway pathology explained the clinical presentations in these case series and did not indicate a need for a lung biopsy to look for small airway pathology. The patients with bronchiolitis had nonspecific radiographical findings and a lack of large airway pathology to explain their respiratory symptoms, which lead to their open lung biopsy. Only one patient with bronchiolitis had chronic bronchitis found on bronchoscopy (3). Our patient had tracheobronchitis identified during his bronchoscopy and bronchiectasis on repeat CT scan following therapy.

This case is a unique presentation of anatomic involvement of both small and large airways, with constrictive bronchiolitis, tracheobronchitis and bronchiectasis associated with enteropathic articular manifestations in a postcolectomy ulcerative colitis patient with a positive rheumatoid factor and ANA. The clinical presentation and pathology results expand the possible spectrum of ulcerative colitis-associated pulmonary complications.

\section{REFERENCES}

1. Kraft SC, Earle RH, Roesler M, Esterly JK. Unexplained bronchopulmonary disease with inflammatory bowel disease. Arch Intern Med 1976;136:454-9.

2. Camus P, Piard F, Ashcroft T, Gal AA, Colby TV. The lung in inflammatory bowel disease. Medicine 1993;72:151-83.

3. Desai SJ, Gephardt GN, Stoler JK. Diffuse panbronchiolitis preceding ulcerative colitis. Chest 1989;95:1342-4.

4. Spira A, Grossman R, Balter M. Large airway disease associated with inflammatory bowel disease. Chest 1998;113:1723-6.

5. Wilcox P, Miller R, Miller G, et al. Airway involvement in ulcerative colitis. Chest 1987;92:18-22.

6. Hilling GAL, Robertson DAF, Chalmers AH, Ruby HS. Unusual pulmonary complications of ulcerative colitis with a rapid response to corticosteroids: case report. Gut 1994:35:847-8.

7. Yaffe BH, Korelitz BI. Sulfasalazine pneumonitis. Am J Gastroenterol 1983;78:493-4.

8. Reinoso M, Schroeder K, Pisani R. Lung disease associated with orally administered mesalamine for ulcerative colitis. Chest 1992;101:1469-71

9. Schwartzman KJ, Bowie DM, Yeadon C, Fraser R, Sutton ED, Levy RD. Constrictive bronchiolitis obliterans following gold therapy for psoriatic arthritis. Eur Respir J 1995;8:2191-3.

10. Tzanakis N, Bouros D, Samiou M, et al. Lung function in patients with inflammatory bowel disease. Respir Med 1998;92:516-22.

11. MacDermott RP, Schreiber S, Nash GS, Koopman WJ. Increased spontaneous secretion of rheumatoid factor by intestinal lamina propria mononuclear cells from Crohn's disease but not ulcerative colitis patients. Clin Exp Immunol 1993;92:152-7.

12. Nielsen H, Binder V, Daugharty H, Svehag SE. Circulating immune complexes in ulcerative colitis: correlation to disease activity. Clin Exp Immunol 1978;11:72-80

13. Zauli D, Crespi C, Dall'Amore P, Bianchi FB, Pisi E. Antibodies to the cytoskeleton components and other autoantibodies in inflammatory bowel disease. Digestion 1985;32:140-4.

14. Habeeb MA, Rajalingam R, Dhar A, Kumar A, Sharma MP, Mehra NK. HLA associated and occurrence of autoantibodies in Asian-Indian patients with ulcerative colitis. Am J Gastroenterol 1997;92:772-6.

15. Colby TV. Bronchiolitis: pathologic considerations. Am J Clin Pathol 1998;109:101-9. 


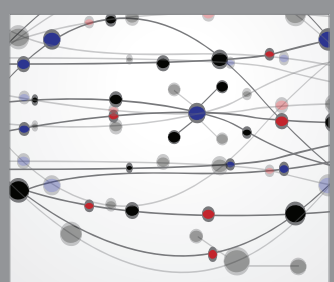

The Scientific World Journal
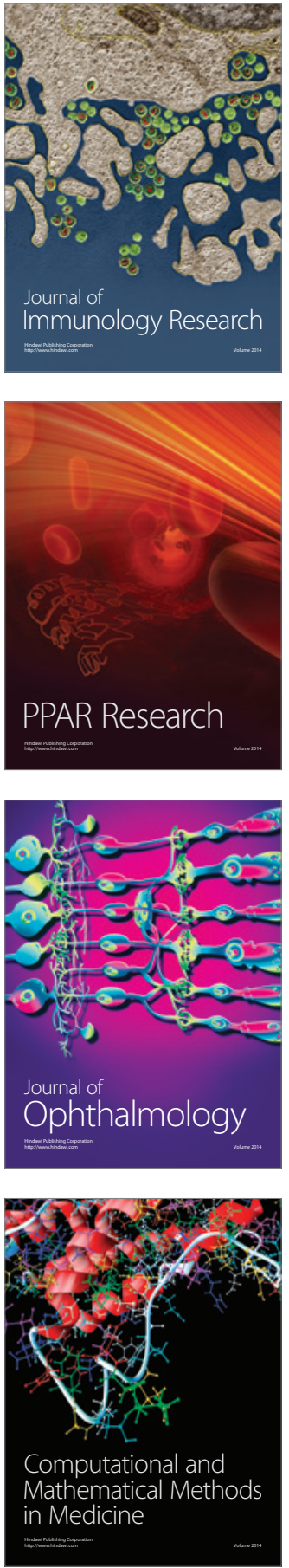

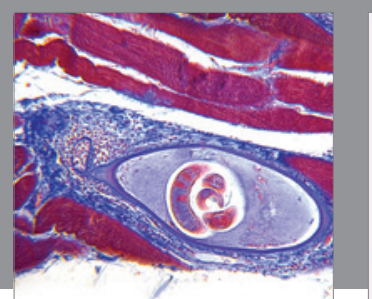

Gastroenterology Research and Practice

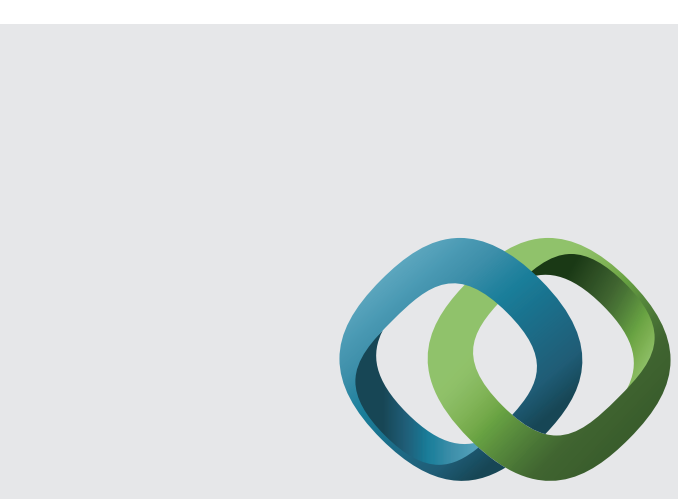

\section{Hindawi}

Submit your manuscripts at

http://www.hindawi.com
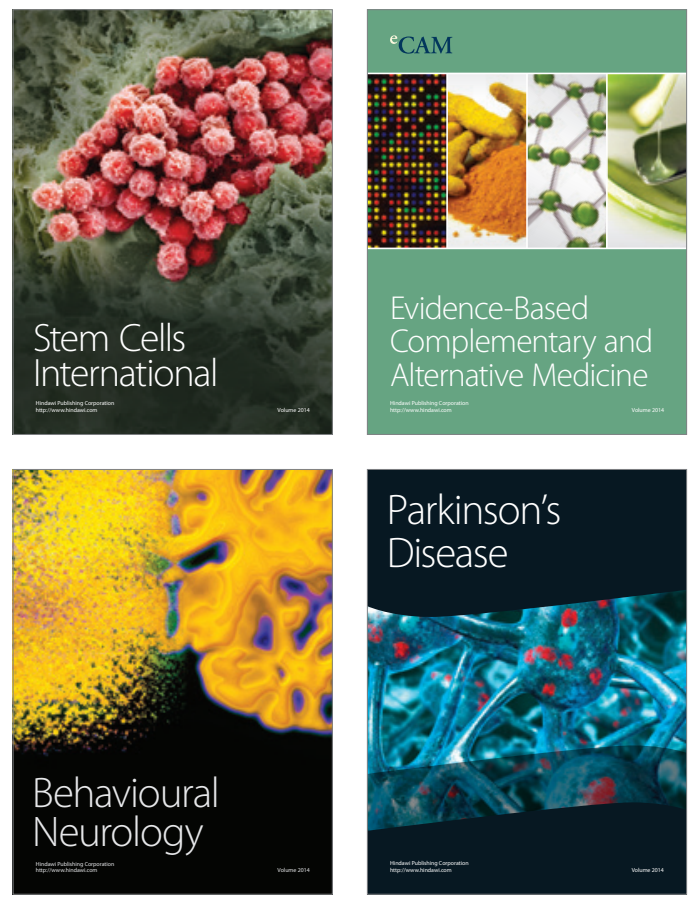
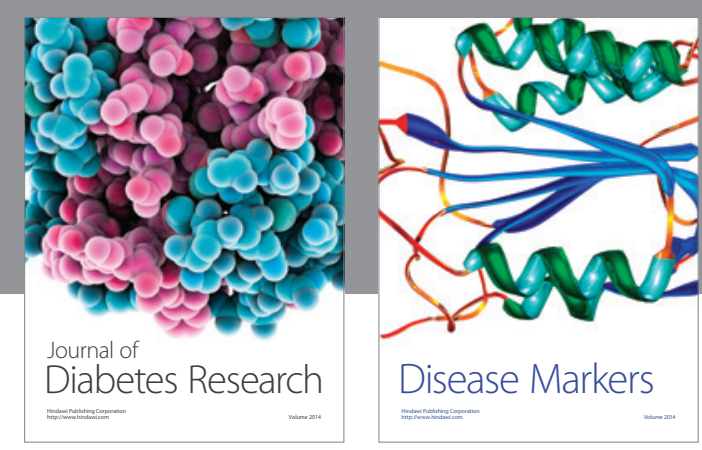

Disease Markers
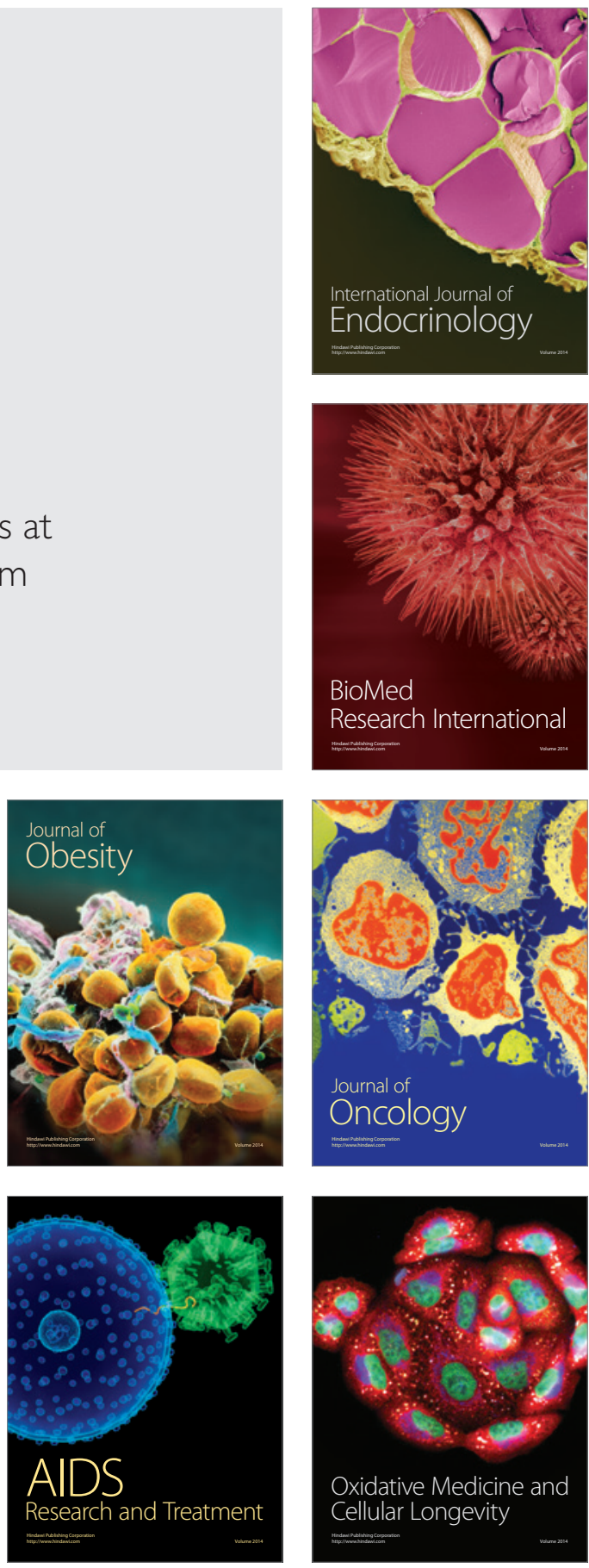